DOI:10.5216/cab.v15i1.13974

\title{
INOCULAÇÃO DE MALTOSE E/OU SACAROSE EM OVOS LEVES EMBRIONADOS
}

\author{
Rodrigo Afonso Leitão ${ }^{1}$, NAdja Susana Mogyca Leandro ${ }^{2}$, José Henrique StringhinI ${ }^{2}$, \\ Marcos Barcellos Café ${ }^{2}$, Maíra Silva Matos ${ }^{3}$, MARia AuXiliadora ANDrade ${ }^{2}$ \\ ${ }^{1}$ Professor Doutor do Instituto Federal do Triângulo Mineiro, Uberaba, MG, Brasil \\ ${ }^{2}$ Professores Doutores da Universidade Federal de Goiás, Goiânia, GO, Brasil. mogyca@ufg.br \\ ${ }^{3}$ Zootecnista Mestre do Serviço Nacional de Aprendizagem Rural, Goiânia, GO, Brasil.
}

\begin{abstract}
Foram estudados os parâmetros de incubação, maturidade gastrintestinal e desempenho até 14 dias de pintos de corte oriundos de ovos leves $(55,82 \pm 1,64 \mathrm{~g})$ inoculados com maltose e/ou sacarose, aos 16 dias de incubação. Os tratamentos compreenderam ovos íntegros $\mathrm{e}$ ovos suplementados com $0,6 \mathrm{~mL}$ de solução de maltose $68 \mathrm{~g} / \mathrm{L}$; com maltose $136 \mathrm{~g} / \mathrm{L}$; com maltose $204 \mathrm{~g} / \mathrm{L}$; com maltose e sacarose $(68 \mathrm{~g} / \mathrm{L}+68 \mathrm{~g} / \mathrm{L})$. O delineamento utilizado foi em blocos casualizados com cinco tratamentos e 120 repetições, sendo um ovo a unidade experimental e para desempenho seis repetições e dez aves por parcela. Os dados foram submetidos ao proc glm do SAS e ao teste de

Tukey $(\mathrm{P}<0,05)$. A inoculação de carboidratos aumentou os períodos requeridos para bicagem da membrana interna, da casca e para eclosão As suplementações com maltose ou maltose+sacarose não interferiram na eclodibilidade e no peso do neonato. O nível de $68 \mathrm{~g} / \mathrm{L}$ de maltose proporcionou maior altura de vilo no primeiro dia de vida, entretanto, esse efeito não foi observado com 10 dias de idade. O nível de $204 \mathrm{~g} / \mathrm{L}$ prejudicou o desenvolvimento gastrintestinal de pintos. Ovos leves inoculados com maltose combinada ou não com sacarose não resultam em pintos com maior desempenho na fase inicial.
\end{abstract}

PALAVRAS-CHAVE: alimentação in ovo; histomorfometria; incubação; matrizes jovens; pintos leves.

\section{EFFECT OF MALTOSE AND SUCROSE SUPPLEMENTATION ON EMBRYONIC LIGHT EGGS}

\section{ABSTRACT}

Hatchery parameters, performance of chicks on initial phase (until 14 days) and intestinal maturity of birds from light eggs supplemented with maltose and sucrose were studied. The treatments were as follows: eggs without supplementation; eggs with $0.6 \mathrm{~mL}$ of maltose solution $(68 \mathrm{~g} / \mathrm{L})$; eggs with $0.6 \mathrm{~mL}$ of maltose solution $(136 \mathrm{~g} / \mathrm{L})$; eggs with $0.6 \mathrm{~mL}$ of maltose solution $(204 \mathrm{~g} / \mathrm{L})$; and eggs with $0.6 \mathrm{~mL}$ of maltose solution $(68 \mathrm{~g} / \mathrm{L})$ and sucrose $(68$ $\mathrm{g} / \mathrm{mL}$ ). The supplementation took place on the $16^{\text {th }}$ day of incubation. The experimental design used was randomized blocks with five treatments and 120 replicates and as for performance we used randomized blocks with four treatments and six replicates and ten birds in each experimental unit. The supplementation did not affect eclodibility, chick weight, and intestinal development of light chicks. Simple or combined maltose egg supplementation did not bring benefits to initial performance of birds.

KEYWORDS: incubation; in ovo feeding; intestinal biometry; light chicks; young breeders. 


\section{INTRODUÇÃO}

A aplicação de nutrientes in ovo para frangos de corte tem sido estudada como alternativa para estimular o desenvolvimento fisiol.[ogico e morfológico. Christensen et al. (1) selecionaram os carboidratos como importante componente para alimentação em ovo devido à importância desse nutriente. Os carboidratos são utilizados como fonte de glicose, o que é crucial para a eclosão (2), quando os estoques de glicogênio diminuem.

De acordo com Tako et al. (3), vários fatores podem limitar o desenvolvimento e a viabilidade dos embriões na fase pré-eclosão e de pintos recémeclodidos: 1) o conteúdo de nutrientes para o desenvolvimento de tecidos e reservas do embrião; 2) a habilidade do trato gastrintestinal para digerir nutrientes de dietas exógenas ricas em proteínas e carboidratos e 3) a habilidade dos pintos em substituir os nutrientes do saco da gema pelos da dieta no período pós-eclosão.

A suplementação de carboidratos pode disponibilizar mais glicose para completar a eclosão e ou o armazenamento para subsequente desenvolvimento (4). Foye et al. (5) estudaram perus oriundos de ovos inoculados com carboidratos e verificaram maior quantidade de glicogênio no músculo do peito em relação aos valores observados no grupo controle, sem suplementação de carboidratos.

O método de "alimentação precoce" e/ou "alimentação in ovo" pode ajudar a suprir alguma deficiência nutricional dos embriões e possibilitar ao pinto de corte atingir todo o potencial de crescimento (3), principalmente nos primeiros dias de idade, quando há maior crescimento relativo.

A suplementação de nutrientes em ovo também pode estimular o desenvolvimento precoce da estrutura da mucosa do intestino delgado, já que, de acordo com Tarachai e Yamauchi (6), a mucosa intestinal não responde somente ao estímulo físico, mas primeiramente às características químicas dos nutrientes. A suplementação de nutrientes via ovo pode aumentar a capacidade de digestão e de absorção do intestino (7). Em estudo realizado por Tako et al. (3), a suplementação em ovo de solução salina contendo maltose, sacarose e dextrina aumentou a atividade de maltase na borda em escova do intestino delgado e promoveu maior desenvolvimento das vilosidades, a partir de 48 horas após a suplementação (com 17,5 dias de incubação).

$\mathrm{O}$ maior desenvolvimento das vilosidades intestinais no final da incubação pode aumentar o aproveitamento dos nutrientes levando a melhores resultados de eclodibilidade $(4,8)$ e desempenho para pintos de corte $(4,9)$. Foi demonstrado que a suplementação de carboidratos em ovo aumenta os níveis de insulina no sangue, o que proporciona maior estímulo à proliferação epitelial do intestino (10).

A produção de pintos com qualidade é um processo complexo e abrangente que envolve muitos fatores. Dentre os aspectos físicos de qualidade do pinto comercializado com um dia, o peso vivo é um fator relevante a se considerar. Ovos menores e mais leves são características de lotes de matrizes jovens (11), com menor deposição de albume e gema no ovo durante o processo de formação, o que pode disponibilizar poucos nutrientes para o crescimento do embrião (12). Como o peso do pinto varia de 61,5 a $76 \%$ do peso inicial do ovo de origem (13), matrizes jovens produzem pintos menos desenvolvidos e de qualidade inferior, quando são julgados pela mortalidade e desempenho $(14,15,16)$.

Este estudo foi realizado para verificar o efeito da suplementação de carboidratos (maltose combinada ou não com sacarose) em ovos embrionados (16 dias de incubação) sobre a eclobilidade, qualidade do neonato, maturidade intestinal e o desempenho inicial de pintos oriundos de ovos leves, ou seja, de matrizes jovens.

\section{MATERIAL E MÉTODOS}

A pesquisa foi conduzida na Escola de Veterinária e Zootecnia da Universidade Federal de Goiás no ano de 2008 para verificar os efeitos da inoculação de carboidratos em ovos embrionados nos períodos de incubação e pós-eclosão. No ensaio de incubação, foram utilizados 600 ovos provenientes de matrizes da linhagem Cobb-500, com 29 semanas de idade, e distribuídos em seis incubadoras automáticas da marca Premium Ecológica, com capacidade para 120 ovos cada. As incubadoras foram mantidas com temperatura de $37,5^{\circ} \mathrm{C}$ e $60 \%$ de umidade relativa, durante todo o período de incubação. Os ovos foram pesados (peso médio de $55,82 \pm 1,64 \mathrm{~g}$ ), numerados e distribuídos em delineamento em blocos casualizados, com cinco tratamentos e 120 repetições, sendo cada ovo considerado uma parcela e os blocos as incubadoras.

Os tratamentos estudados foram: ovo íntegro (controle); inoculado com $0,6 \mathrm{~mL}$ de solução de maltose $68 \mathrm{~g} / \mathrm{L}(506 \mathrm{mOsm} / \mathrm{L})$; inoculado com 0,6 $\mathrm{mL}$ de solução de maltose $136 \mathrm{~g} / \mathrm{L}(708 \mathrm{mOsm} / \mathrm{L})$; inoculado com $0,6 \mathrm{~mL}$ de solução de maltose 204 $\mathrm{g} / \mathrm{L}(904 \mathrm{mOsm} / \mathrm{L})$; inoculado com $0,6 \mathrm{~mL}$ de solução de maltose $68 \mathrm{~g} / \mathrm{L}+$ sacarose $68 \mathrm{~g} / \mathrm{L}(708$ $\mathrm{mOsm} / \mathrm{L}$ ). Nos quatro tratamentos envolvendo inoculação, os carboidratos foram diluídos em solução $\mathrm{NaCl}-0,9 \%$ (solução salina) no momento da inoculação. Foram utilizados ovos íntegros como 
tratamento controle, pois, de acordo com Leitão et al. (17), não foram constatadas diferenças entre os tratamentos utilizando ovos íntegros $\mathrm{e}$ ovos suplementados com água ou solução salina. A inoculação foi realizada via cavidade alantóide, aos 16 dias de incubação (D16). Os ovos ficaram expostos à temperatura média ambiente de $27^{\circ} \mathrm{C}$ e foram submetidos à ovoscopia aproximadamente 5 minutos, evitando-se lesionar o embrião.

Para a ovoscopia, os ovos brancos foram eliminados. O procedimento foi realizado a cada três horas, iniciando às 456 horas de incubação, o ovo foi acondicionado em saquinho de filó quando era constatada a bicagem da membrana interna, possibilitando a pesagem da casca e do pinto após a eclosão. Por meio do procedimento foram determinadas as seguintes variáveis: a) período da bicagem da membrana interna: número de horas necessárias à ruptura da membrana interna; b) período da bicagem da casca ou membrana externa: número de horas necessárias à ruptura da casca ou membrana externa; c) período da eclosão: número de horas necessárias para o momento em que ocorre a eclosão do ovo; d) período de retirada: horas necessárias para o momento da retirada do pinto do nascedouro (quando o pinto estava seco). Os ovos brancos foram eliminados.

Após a eclosão as seguintes variáveis foram avaliadas: a) frequência da mortalidade embrionária: número de embriões mortos antes e após a suplementação; b) percentagem de eclosão (eclodibilidade): percentual de pintos eclodidos em relação ao número de ovos férteis; c) peso ao nascer (penugem seca); d) relação peso do pinto/peso do ovo: peso do pinto ao nascer expresso como porcentagem do peso do ovo.

Para avaliação do período pós-eclosão, os 300 pintos foram alojados em um galpão de alvenaria dentro de baterias de arame galvanizado, com cinco andares, munidos de comedouros e bebedouros tipo calha. A ração utilizada foi farelada, composta principlamente de milho e farelo de soja, para atender os níveis nutricionais da fase pré-inicial (21,9\% PB e $2.950 \mathrm{kcal}$ de $\mathrm{EM} / \mathrm{kg}$ de ração), de acordo com Rostagno et al. (18). A ração e a água foram fornecidas à vontade durante todo o período. As aves e as rações foram pesadas nos períodos de um a quatro, um a sete, um a dez e um a 14 dias de idade para estudar as variáveis de desempenho, sendo a conversão alimentar corrigida pelo peso dos pintos mortos.

Foi utilizado o delineamento em blocos casualizados (dois blocos, de machos e de fêmeas), com cinco tratamentos, seis repetições e dez aves por parcela experimental. Os tratamentos foram representados pelos pintos oriundos das diferentes suplementações durante o período de incubação.

No primeiro e décimo dia de vida foram estudadas a biometria dos órgãos do trato gastrintestinal (TGI). Para tanto, um pinto por parcela foi pesado, sacrificado pelo deslocamento cervical e o TGI foi coletado para a determinação do peso do pâncreas, do fígado, do resíduo vitelino, do intestino grosso (cecos, cólon e reto) e peso e comprimento do intestino delgado (porção compreendida entre o piloro e a junção íleo-cecocólica). Os valores de peso obtidos foram convertidos em porcentagem do peso corporal dos pintos.

Para a histomorfometria intestinal foi colhido, de cada uma das regiões (duodeno, jejuno e íleo), um fragmento de aproximadamente dois centímetros de comprimento, aberto longitudinalmente, estirado em pedaço de isopor, preso em grampos e fixado em solução de formalina neutra tamponada a $10 \%$. Após $24 \mathrm{~h}$ de fixação, os fragmentos foram transferidos para solução de álcool $70 \%$ e, posteriormente, foram corados pelo método de Hematoxilina - Eosina (HE). As medidas morfométricas foram determinadas utilizando-se o programa analisador de imagens Axion Vision 3.0 $\left(\right.$ Zeiss $\left.^{\circledR}\right)$. As imagens das lâminas foram digitalizadas do microscópio óptico de campo claro (Carl Zeiss modelo JENAVAL) para computador. As medidas de altura de vilosidade foram tomadas a partir da sua região basal, coincidente com a porção superior das criptas, até seu ápice, e a profundidade de cripta foi definida como a profundidade da invaginação da cripta com os vilos adjacentes, de acordo com Uni et al. (19). Foram efetuadas seis medidas de altura de vilos e profundidade de criptas por lâmina, totalizando 36 repetições por tratamento.

Os dados foram submetidos à análise de variância com auxílio do sistema de análise estatística (20) e as médias comparadas pelo teste de Tukey a 5\% de probabilidade. Para os dados de mortalidade embrionária, foi aplicado o teste de quiquadrado de acordo com Sampaio (21), sendo cada ovo considerado uma repetição. Os dados de mortalidade pós-eclosão e a porcentagem de resíduo vitelino, aos dez dias de idade, foram transformados em Arc seno $((\% \mathrm{M} / 100)+0,05)^{0,5}$, sendo $\mathrm{M}$ a taxa de mortalidade.

\section{RESULTADOS E DISCUSSÃO}

A suplementação com maltose ou maltose combinada com sacarose proporcionou atraso nos períodos de bicagem interna, externa, eclosão e retirada do nascedouro em relação ao grupo controle. Para os ovos íntegros, o tempo necessário para o 
período de eclosão e o período da retirada da incubadora foi inferior aos demais tratamentos (Tabela 1). Resultados semelhantes foram observados por Leitão et al. (17), sendo que os ovos inoculados aos 16 dias de incubação com glicose (em solução aquosa ou salina) dispenderam mais tempo para a bicagem da membrana interna, da casca e para eclosão em relação aos embriões não suplementados.

Tabela 1. Período necessário para bicagem da membrana interna (BMI), bicagem da casca (BC), período de eclosão do ovo (PE) e período de retirada do pinto da incubadora (PR), em horas de incubação, de ovos suplementados ou não com maltose e/ou sacarose

\begin{tabular}{lcccc}
\hline Tratamentos & $\begin{array}{c}\text { BMI } \\
(\mathrm{h})\end{array}$ & $\begin{array}{c}\text { BC } \\
(\mathrm{h})\end{array}$ & $\begin{array}{c}\text { PE } \\
(\mathrm{h})\end{array}$ & $\begin{array}{c}\text { PR } \\
(\mathrm{h})\end{array}$ \\
\hline Ovos íntegros & $468,7 \mathrm{c}$ & $474,3 \mathrm{c}$ & $489,8 \mathrm{~b}$ & $500,7 \mathrm{c}$ \\
Maltose $68 \mathrm{~g} / \mathrm{L}$ & $473,1 \mathrm{bc}$ & $479,3 \mathrm{~b}$ & $494,0 \mathrm{a}$ & $504,9 \mathrm{~b}$ \\
Maltose $136 \mathrm{~g} / \mathrm{L}$ & $477,9 \mathrm{a}$ & $483,0 \mathrm{ab}$ & $496,7 \mathrm{a}$ & $507,6 \mathrm{ab}$ \\
Maltose $204 \mathrm{~g} / \mathrm{L}$ & $478,6 \mathrm{a}$ & $484,3 \mathrm{a}$ & $497,3 \mathrm{a}$ & $508,6 \mathrm{a}$ \\
Maltose $68 \mathrm{~g} / \mathrm{L}+$ sacarose $68 \mathrm{~g} / \mathrm{L}$ & $474,9 \mathrm{ab}$ & $479,3 \mathrm{~b}$ & $494,9 \mathrm{a}$ & $506,2 \mathrm{ab}$ \\
\hline CV $(\%)$ & 2,18 & 2,12 & 1,81 & 1,55 \\
Valor de P & 0,0001 & 0,0001 & 0,0001 & 0,0001 \\
\hline Médias segudas de men letra não diferm pelo teste de Tukey $(\mathrm{P}<0,05)$ & & & &
\end{tabular}

Médias seguidas de mesma letra não diferem pelo teste de Tukey $(\mathrm{P}<0,05)$.

A suplementação de maltose, associada ou não à sacarose, não interferiu $(\mathrm{P}>0,05)$ na mortalidade embrionária, assim como não influenciou a eclodibilidade (Tabela 2). Pode-se observar que os ovos íntegros apresentaram menor período de eclosão e retirada dos pintos do nascedouro $(\mathrm{p}<0,05)$. O atraso observado nos ovos inoculados pode estar relacionado à retirada dos ovos da incubadora no período da inoculação, o que pode ter causado uma redução na temperatura dos ovos, ou mesmo o fato de a solução ter sido injetada em temperatura ambiente, ou seja, abaixo da temperatura do ovo.

Tabela 2. Frequência da mortalidade embrionária em número de ovos e eclodibilidade em porcentagem, em ovos embrionados suplementados com maltose e/ou sacarose

\begin{tabular}{lcccc}
\hline \multirow{2}{*}{ Tratamentos } & \multicolumn{3}{c}{ Mortalidade embrionária } & \\
\cline { 2 - 4 } & $\begin{array}{c}\text { antes-inoculação } \\
(\mathrm{n}=120)\end{array}$ & $\begin{array}{c}\text { Após-inoculação } \\
(\mathrm{n}=120)\end{array}$ & Total & $\begin{array}{c}\text { Eclodibilidade } \\
(\%)\end{array}$ \\
\hline Ovos íntegros & 10 & 7 & 17 & 78,3 \\
Maltose $68 \mathrm{~g} / \mathrm{L}$ & 5 & 9 & 14 & 82,3 \\
Maltose $136 \mathrm{~g} / \mathrm{L}$ & 3 & 10 & 13 & 73,6 \\
Maltose $204 \mathrm{~g} / \mathrm{L}$ & 6 & 18 & 24 & 73,7 \\
Maltose+sacarose & 5 & 13 & 18 & 72,5 \\
Total & 29 & 57 & 86 & \\
\hline CV $(\%)$ & & & & 12,79 \\
Valor de $\mathrm{P}$ & & & & 0,406 \\
\hline
\end{tabular}

*Qui-Quadrado $(\mathrm{P}<0,05)$ tabelado=9,49 Mortalidade embrionária calculado=6,58.

O resultado de eclodibilidade corrobora com Uni et al. (9) que, suplementando ovos embrionados com solução contendo maltose, sacarose, dextrina e $\beta$-hidroxi- $\beta$-metilbutirato, não verificaram aumento na eclodibilidade dos ovos suplementados. No entanto, alguns trabalhos têm demonstrado que a suplementação de ovos com aminoácidos (22) ou com carboidratos (maltose, sacarose e dextrina) (4) proporcionou resultados positivos na eclodibilidade $\mathrm{e}$ ou qualidade de pinto.

A mortalidade embrionária não foi afetada, mesmo no tratamento com maltose a $204 \mathrm{~g} / \mathrm{L}$ com concentração de $904 \mathrm{mOsm} / \mathrm{L}$, ou seja, acima de 800 $\mathrm{mOsm} / \mathrm{L}$, concentração máxima para soluções a 
serem inoculadas em ovo de acordo com a recomendação de Uni e Ferket (4). No entanto, (17) verificaram aumento na mortalidade embrionária em embriões suplementados aos 16 dias de incubação com glicose numa concentração de $926 \mathrm{mOsm} / \mathrm{L}$.

A suplementação com maltose $136 \mathrm{~g} / \mathrm{L}$ proporcionou maior $(\mathrm{P}<0,05)$ relação peso do pinto/peso do ovo quando comparada aos ovos íntegros (Tabela 3). Esse resultado não concorda com os dados de Pedroso et al. (23) que, suplementando diferentes níveis de glicose em ovo, não encontraram diferenças para relação peso do pinto/peso do ovo em relação ao grupo não suplementado. As diferenças nos resultados podem estar relacionadas com o tipo de carboidrato utilizado na suplementação dos embriões aos 16 dias de idade.

Não houve efeito $(\mathrm{P}>0,05)$ da suplementação da maltose ou maltose associada com sacarose sobre o peso do pinto ao nascer (Tabela 3). No entanto, Uni et al. (9) encontraram maior peso ao nascer para pintos oriundos de ovos suplementandos com solução contendo maltose, sacarose, dextrina e $\beta$ hidroxi- $\beta$-metilbutirato. Também Leitão et al. (24) encontraram maiores pesos ao nascer dos pintos oriundos de ovos suplementados com maltose, sacarose ou glicose em relação aos pintos provenientes de ovos íntegros. Esses resultos sugerem que a dosagem de $136 \mathrm{~g} / \mathrm{L}$ de maltose foi melhor.

Tabela 3. Relação entre peso do pinto e peso do ovo (PP/PO), expressa em porcentagem, de ovos embrionados suplementados com maltose e/ou sacarose e peso dos pintos ao nascer (PN)

\begin{tabular}{lcc}
\hline Tratamentos & PP/PO & PN \\
& $(\%)$ & $(\mathrm{g})$ \\
\hline Ovo íntegro & $72,8 \mathrm{~b}$ & 40,7 \\
Maltose $68 \mathrm{~g} / \mathrm{L}$ & $73,3 \mathrm{ab}$ & 40,9 \\
Maltose $136 \mathrm{~g} / \mathrm{L}$ & $74,2 \mathrm{a}$ & 41,6 \\
Maltose $204 \mathrm{~g} / \mathrm{L}$ & $74,0 \mathrm{ab}$ & 41,4 \\
Maltose $68 \mathrm{~g} / \mathrm{L}+$ sacarose $68 \mathrm{~g} / \mathrm{L}$ & $73,8 \mathrm{ab}$ & 41,1 \\
\hline CV $(\%)$ & 3,74 & 1,64 \\
Valor de P & 0,007 & 0,208 \\
\hline
\end{tabular}

Médias seguidas de mesma letra não diferem pelo teste de Tukey $(\mathrm{P}<0,05)$.

Não houve efeito da suplementação dos ovos $(\mathrm{P}>0,05)$ sobre o desempenho nas diferentes idades estudadas (Tabela 4). Houve perda de peso dos pintos no período da retirada da máquina de eclosão até o momento de alojamento, para todos os tratamentos, o que era esperado. Embora a suplementação de maltose a $136 \mathrm{~g} / \mathrm{L}$ tenha proporcionado melhor relação pinto/ovo, a suplementação não proporcionou ganho no desempenho na fase pré-inicial de criação. Do mesmo modo, Foye et al. (5) constataram maior peso ao nascer de pintos oriundos de ovos inoculados com maltose e dextrina, entretanto esta superioridade não se manteve a partir de três dias de vida.

Pintos poderiam alcançar melhor desempenho se fosse utilizado uma combinação de carboidratos para suplementação em ovo (4). Uni e Ferket (4) estudaram três carboidratos combinados (maltose, sacarose e dextrina) e, em outras pesquisas $(9,3)$, combinaram maltose, sacarose, dextrina e $\beta$ hidroxi- $\beta$-metilbutirato e, em todos os estudos, observaram melhor desempenho dos pintos oriundos de ovos suplementados. A mistura de $\beta$-hidroxi- $\beta$ metilbutirato com carboidratos elevou os níveis da atividade de sacarase e estimulou a proliferação de enterócitos, promovendo maior aproveitamento dos nutrientes e, consequentemente, melhor desempenho (3).

Não foram encontradas diferenças $(\mathrm{P}>0,05)$ entre os tratamentos para biometria dos órgãos do trato gastrintestinal dos pintos com um e dez dias de vida (Tabelas 5), ou seja, as suplementações realizadas não estimularam o aumento do peso dos órgãos analisados.

Esses dados corroboram com Pedroso et al. (23), que suplementaram ovos com diferentes níveis de glicose $(100,200$ e $300 \mathrm{mg})$ no $16^{\circ}$ dia de incubação e não encontraram influência da glicose suplementada no desenvolvimento desses órgãos. Pode-se observar que os valores de coeficientes de variação encontrados para as variáveis de biometria de órgãos foram relativamente elevados, embora esses valores se assemelhem aos coeficientes encontrados por Pedroso et al. (23), e podem ser inerentes à própria variável estudada.

O desenvolvimento dos vilos e criptas foram influenciados pelos tratamentos $(\mathrm{P}<0,05)$ em pintos com um dia de idade (Tabela 6), sendo que a 
suplementação com maltose $68 \mathrm{~g} / \mathrm{L}$ propiciou maior desenvolvimento dos vilos do duodeno e íleo em relação aos pintos oriundos de ovos não suplementados. Quando foi utilizada maltose 204 $\mathrm{g} / \mathrm{L}$, os vilos do jejuno e do íleo apresentaram menor desenvolvimento em relação àqueles dos pintos suplementados com maltose $68 \mathrm{~g} / \mathrm{L}$. Na concentração de $136 \mathrm{~g} / \mathrm{L}$ de maltose ou na combinação de maltose com a sacarose não foi observado efeito positivo. Tako et al. (3) constatou maior comprimento dos vilos do jejuno em pintos com um dia de idade oriundos de ovos suplementados com mistura de carboidratos contendo maltose, sacarose e dextrina aos 17 dias de incubação.

Tabela 4. Desempenho de pintos de corte, nos períodos de 1 a 4,1 a 7 e 1 a 14 dias de idade, oriundos de ovos leves inoculados com maltose e/ou sacarose

\begin{tabular}{|c|c|c|c|c|c|c|}
\hline \multicolumn{7}{|c|}{1 a 4 dias de idade } \\
\hline Tratamentos & $\begin{array}{l}\text { Peso } \\
\text { alojamento } \\
\text { (g) }\end{array}$ & $\begin{array}{l}\text { Peso } \\
\text { corporal } \\
(\mathrm{g})\end{array}$ & $\begin{array}{l}\text { Ganho } \\
\text { Peso } \\
\text { (g) }\end{array}$ & $\begin{array}{l}\text { Consumo de } \\
\text { Ração } \\
\text { (g) }\end{array}$ & $\begin{array}{l}\text { Conversão } \\
\text { Alimentar } \\
(\mathrm{g} / \mathrm{g})\end{array}$ & $\begin{array}{l}\text { Mort* } \\
(\%)\end{array}$ \\
\hline Ovo íntegro & 37,9 & 64,2 & 26,2 & 26,0 & 0,992 & 0,0 \\
\hline Maltose $68 \mathrm{~g} / \mathrm{L}$ & 38,8 & 66,0 & 26,5 & 25,5 & 0,949 & 1,5 \\
\hline Maltose $136 \mathrm{~g} / \mathrm{L}$ & 38,2 & 64,8 & 26,1 & 25,8 & 0,996 & 0,0 \\
\hline Maltose $204 \mathrm{~g} / \mathrm{L}$ & 39,6 & 64,6 & 25,0 & 25,6 & 1,027 & 0,0 \\
\hline $\begin{array}{l}\text { Maltose } 68 \mathrm{~g} / \mathrm{L}+\text { sacarose } \\
68 \mathrm{~g} / \mathrm{L}\end{array}$ & 38,7 & 63,1 & 24,4 & 23,9 & 0,983 & 0,0 \\
\hline CV $(\%)$ & 2,94 & 3,66 & 10,88 & 10,93 & 10,52 & 12,60 \\
\hline Valor de P & 0,149 & 0,356 & 0,668 & 0,706 & 0,785 & 0,427 \\
\hline \multicolumn{7}{|c|}{1 a 7 dias de idade } \\
\hline Tratamentos & & $\begin{array}{l}\text { Peso } \\
\text { corporal } \\
(\mathrm{g}) \\
\end{array}$ & $\begin{array}{l}\text { Ganho de } \\
\text { Peso } \\
(\mathrm{g}) \\
\end{array}$ & $\begin{array}{l}\text { Consumo } \\
\text { Ração } \\
(\mathrm{g}) \\
\end{array}$ & $\begin{array}{l}\text { de Conversão } \\
\text { Alimentar } \\
(\mathrm{g} / \mathrm{g}) \\
\end{array}$ & $\begin{array}{l}\text { Mort* } \\
(\%)\end{array}$ \\
\hline Ovo íntegro & & 116,3 & 78,3 & 91,5 & 1,169 & 0,00 \\
\hline Maltose $68 \mathrm{~g} / \mathrm{L}$ & & 117,1 & 77,6 & 91,3 & 1,174 & 1,51 \\
\hline Maltose $136 \mathrm{~g} / \mathrm{L}$ & & 115,3 & 76,5 & 91,5 & 1,197 & 0,00 \\
\hline Maltose $204 \mathrm{~g} / \mathrm{L}$ & & 115,7 & 76,1 & 92,0 & 1,212 & 0,00 \\
\hline Maltose $68 \mathrm{~g} / \mathrm{L}+$ sacarose & $68 \mathrm{~g} / \mathrm{L}$ & 113,0 & 74,3 & 86,9 & 1,172 & 0,00 \\
\hline CV $(\%)$ & & 3,71 & 5,88 & 6,69 & 6,41 & 12,60 \\
\hline Valor de P & & 0,546 & 0,589 & 0,584 & 0,819 & 0,427 \\
\hline \multicolumn{7}{|c|}{1 a 14 dias de idade } \\
\hline Tratamentos & & $\begin{array}{l}\text { Peso } \\
\text { Vivo } \\
\text { (g) }\end{array}$ & $\begin{array}{l}\text { Ganho Peso } \\
\text { (g) }\end{array}$ & $\begin{array}{l}\text { Consumo } \\
\text { Ração } \\
(\mathrm{g})\end{array}$ & $\begin{array}{l}\text { Conversão } \\
\text { Alimentar } \\
(\mathrm{g} / \mathrm{g})\end{array}$ & $\begin{array}{l}\text { Mort* } \\
(\%)\end{array}$ \\
\hline Ovo íntegro & & 332,9 & 294,9 & 381,9 & 1,339 & 0,0 \\
\hline Maltose $68 \mathrm{~g} / \mathrm{L}$ & & 334,8 & 295,9 & 382,5 & 1,346 & 3,0 \\
\hline Maltose $136 \mathrm{~g} / \mathrm{L}$ & & 331,1 & 292,9 & 383,6 & 1,366 & 1,5 \\
\hline Maltose $204 \mathrm{~g} / \mathrm{L}$ & & 329,8 & 290,2 & 386,4 & 1,386 & 0,0 \\
\hline Maltose $68 \mathrm{~g} / \mathrm{L}+$ sacarose $\theta$ & $68 \mathrm{~g} / \mathrm{L}$ & 327,2 & 288,5 & 376,4 & 1,353 & 1,8 \\
\hline CV (\%) & & 3,20 & 3,49 & 3,49 & 3,42 & 23,35 \\
\hline Valor de P & & 0,772 & 0,693 & 0,772 & 0,448 & 0,471 \\
\hline
\end{tabular}

* Valor de $\mathrm{P}$ e CV(\%) da mortalidade transformada para a análise estatística 
Tabela 5. Comprimento (cm) do intestino delgado (CID) e peso do intestino delgado (ID), intestino grosso (IG), pâncreas (PAN), fígado (FÍG) e resíduo vitelino (RV) em relação ao peso corporal (\%) de pintos de corte com 1 e 10 dias de idade, oriundos de ovos suplementados com maltose e/ou sacarose

\begin{tabular}{|c|c|c|c|c|c|c|c|}
\hline \multicolumn{8}{|c|}{1 dia de idade } \\
\hline Tratamentos & $\begin{array}{l}\text { CID } \\
(\mathrm{cm})\end{array}$ & $\begin{array}{l}\text { ID } \\
(\%)\end{array}$ & $\begin{array}{l}\mathrm{IG} \\
(\%)\end{array}$ & $\begin{array}{l}\text { PAN } \\
(\%)\end{array}$ & $\begin{array}{l}\text { FÍG } \\
(\%)\end{array}$ & \multicolumn{2}{|c|}{$\begin{array}{l}\mathrm{RV} \\
(\%)\end{array}$} \\
\hline Ovo íntegro & 32,3 & 2,7 & 0,9 & 0,20 & 2,8 & \multicolumn{2}{|c|}{9,1} \\
\hline Maltose $68 \mathrm{~g} / \mathrm{L}$ & 33,2 & 2,6 & 0,9 & 0,15 & 2,5 & \multicolumn{2}{|c|}{9,8} \\
\hline Maltose $136 \mathrm{~g} / \mathrm{L}$ & 32,2 & 2,6 & 1,1 & 0,16 & 2,4 & \multicolumn{2}{|c|}{10,2} \\
\hline Maltose $204 \mathrm{~g} / \mathrm{L}$ & 30,3 & 2,2 & 0,9 & 0,10 & 2,2 & \multicolumn{2}{|c|}{13,6} \\
\hline $\begin{array}{l}\text { Maltose } 68 \mathrm{~g} / \mathrm{L}+ \\
\text { sacarose } 68 \mathrm{~g} / \mathrm{L}\end{array}$ & 30,3 & 2,7 & 1,3 & 0,15 & 2,3 & \multicolumn{2}{|c|}{8,8} \\
\hline CV $(\%)$ & 15,74 & 19,47 & 33,31 & 46,50 & 15,50 & \multirow{2}{*}{\multicolumn{2}{|c|}{$\begin{array}{l}33,74 \\
0,153\end{array}$}} \\
\hline Valor de P & 0,812 & 0,486 & 0,238 & 0,188 & 0,151 & & \\
\hline \multicolumn{8}{|c|}{10 dias de idade } \\
\hline Tratamentos & $\begin{array}{l}\text { CID } \\
(\mathrm{cm})\end{array}$ & $\begin{array}{l}\text { ID } \\
(\%)\end{array}$ & $\begin{array}{l}\mathrm{IG} \\
(\%)\end{array}$ & $\begin{array}{l}\text { PAN } \\
(\%)\end{array}$ & $\begin{array}{l}\text { FIG } \\
(\%)\end{array}$ & $\begin{array}{l}\mathrm{RV} \\
(\%)\end{array}$ & RVT \\
\hline Ovo íntegro & 85,9 & 7,8 & 1,4 & 0,6 & 4,4 & 0,16 & 0,23 \\
\hline Maltose $68 \mathrm{~g} / \mathrm{L}$ & 91,2 & 9,2 & 1,7 & 0,5 & 4,4 & 0,17 & 0,23 \\
\hline Maltose $136 \mathrm{~g} / \mathrm{L}$ & 86,5 & 7,8 & 1,3 & 0,5 & 4,3 & 0,13 & 0,23 \\
\hline Maltose $204 \mathrm{~g} / \mathrm{L}$ & 88,7 & 8,6 & 1,4 & 0,5 & 4,1 & 0,08 & 0,23 \\
\hline $\begin{array}{l}\text { Maltose } 68 \mathrm{~g} / \mathrm{L}+ \\
\text { sacarose } 68 \mathrm{~g} / \mathrm{L}\end{array}$ & 89,2 & 8,4 & 1,5 & 0,6 & 4,1 & 0,03 & 0,23 \\
\hline $\mathrm{CV}(\%)$ & 12,8 & 12,97 & 39,59 & 14,47 & 15,62 & 208,40 & 2,32 \\
\hline Valor de P & 0,929 & 0,176 & 0,809 & 0,265 & 0,829 & 0,817 & 0,819 \\
\hline
\end{tabular}

RVT - Valores do Resíduo vitelino transformado para análise estatística

Tabela 6. Altura dos vilos $(\mu \mathrm{m})$ e profundidade de cripta $(\mu \mathrm{m})$ no duodeno, jejuno e íleo de pintos de corte com 1 e 10 dias de idade

\begin{tabular}{|c|c|c|c|c|c|c|}
\hline \multirow[b]{3}{*}{ Tratamentos } & \multicolumn{6}{|c|}{1 dia de idade } \\
\hline & \multicolumn{2}{|l|}{ Duodeno } & \multicolumn{2}{|l|}{ Jejuno } & \multicolumn{2}{|l|}{ Íleo } \\
\hline & Vilo & Cripta & Vilo & Cripta & Vilo & Cripta \\
\hline Ovos íntegros & $236,2 \mathrm{bc}$ & 45,7 & $198,8 \mathrm{ab}$ & 38,4 & $149,4 \mathrm{c}$ & $35,5 \mathrm{bc}$ \\
\hline Maltose $68 \mathrm{~g} / \mathrm{L}$ & 312,8 a & 41,6 & $247,2 \mathrm{a}$ & 40,9 & $216,5 \mathrm{ab}$ & $41,1 \mathrm{ab}$ \\
\hline Maltose $136 \mathrm{~g} / \mathrm{L}$ & $260,0 \mathrm{ab}$ & 46,1 & $193,2 \mathrm{ab}$ & 40,0 & $184,1 \mathrm{bc}$ & $42,4 \mathrm{ab}$ \\
\hline Maltose $204 \mathrm{~g} / \mathrm{L}$ & $253,7 \mathrm{ab}$ & 42,0 & $153,1 \mathrm{bc}$ & 37,4 & $137,8 \mathrm{c}$ & $31,0 \mathrm{c}$ \\
\hline $\begin{array}{l}\text { Maltose } 68 \\
\text { sacarose } 68 \mathrm{~g} / \mathrm{L}\end{array}$ & 308,8 a & 45,6 & $211,1 \mathrm{ab}$ & 44,8 & $174,4 \mathrm{bc}$ & $36,7 \mathrm{bc}$ \\
\hline $\mathrm{CV}(\%)$ & 23,89 & 19,08 & 25,48 & 18,58 & 27,54 & 20,48 \\
\hline \multirow[t]{3}{*}{ Valor de $\mathrm{P}$} & 0,007 & 0,314 & 0,001 & 0,202 & 0,001 & 0,004 \\
\hline & \multicolumn{6}{|c|}{10 dias de idade } \\
\hline & Duodeno & & Jejuno & & Íleo & \\
\hline Tratamentos & Vilo & Cripta & Vilo & Cripta & Vilo & Cripta \\
\hline Ovos íntegros & $1334,6 \mathrm{a}$ & $250,1 \mathrm{a}$ & 703,3 & 173,3 & $544,2 \mathrm{ab}$ & 143,1 \\
\hline Maltose $68 \mathrm{~g} / \mathrm{L}$ & $972,3 \mathrm{~b}$ & $202,5 \mathrm{c}$ & 656,0 & 155,1 & $620,4 \mathrm{a}$ & 165,9 \\
\hline Maltose $136 \mathrm{~g} / \mathrm{L}$ & $1107,2 \mathrm{~b}$ & 209,6 bc & 735,6 & 178,9 & $563,2 \mathrm{ab}$ & 158,3 \\
\hline Maltose $204 \mathrm{~g} / \mathrm{L}$ & $1022,0 \mathrm{~b}$ & $237,1 \mathrm{ab}$ & 684,7 & 181,6 & $500,0 \mathrm{bc}$ & 142,6 \\
\hline $\begin{array}{l}\text { Maltose } 68 \mathrm{~g} / \mathrm{L}+\text { sacarose } \\
68 \mathrm{~g} / \mathrm{L}\end{array}$ & $1018,1 \mathrm{~b}$ & $223,1 \mathrm{abc}$ & 722,9 & 183,8 & $416,5 \mathrm{c}$ & 143,7 \\
\hline CV $(\%)$ & 14,57 & 13,02 & 16,6 & 18,92 & 15,4 & 16,1 \\
\hline Valor de P & 0,0001 & 0,0001 & 0,3536 & 0,1316 & 0,0001 & 0,0769 \\
\hline
\end{tabular}

Médias seguidas de mesma letra não diferem pelo teste de Tukey $(\mathrm{P}<0,05)$. 
Aos 10 dias de idade, não foi observado efeito positivo da suplementação com maltose ou maltose associada com sacarose sobre comprimento de vilos, sendo que os melhores resultados foram observados para pintos oriundos de ovos íntegros. As criptas do duodeno dos pintos oriundos de ovos íntegros mostraram maior desenvolvimento que aquelas de pintos suplementados com maltose $68 \mathrm{~g} / \mathrm{L}$ e $136 \mathrm{~g} / \mathrm{L}$.

De acordo com Tako et al. (3), após a eclosão, acontece rápido desenvolvimento do intestino com o ápice entre o terceiro e o sétimo dia, sendo que, após esse período, essa taxa de crescimento é reduzida. Esses autores afirmaram que o efeito da alimentação em ovo no desenvolvimento morfológico do intestino delgado é máximo até 48 horas após o procedimento de inoculação.

Utilizando ovos de matrizes com 35 semanas ou mais Uni et al. (4), Tako et al. (3) e Uni et al. (9) encontraram resultados favoráveis à suplementação de carboidratos em ovo. As diferenças observadas podem estar relacionadas com muitos fatores, como os carboidratos inoculados, os tipos de associações, dosagens e metodologia de inoculação em ovos utilizada. Embora a suplementação com $68 \mathrm{~g} / \mathrm{L}$ de maltose tenha proporcionado melhor relação peso pinto/peso ovo, os pintos de matrizes jovens (29 semanas) neste trabalho não apresentaram maior peso ao nascer ou melhor desempenho até aos 14 dias de idade.

\section{CONCLUSÕES}

As suplementações de maltose ou combinação de maltose com sacarose não melhoraram a taxa de eclosão e a qualidade do pinto neonato, embora a solução com $68 \mathrm{~g} / \mathrm{L}$ da maltose favoreceu o desenvolvimento gastrintestinal de pintos com um dia de idade.

A suplementação aos D16 com maltose combinada ou não com sacarose não proporcionou melhoras no desempenho na fase pré-inicial de criação de pintos leves, oriundos de matrizes jovens.

\section{REFERÊNCIAS}

1. Christensen, VL, Donaldson, WE, Nestor, KE. Effect of maternal dietary triiodothyronine on embryonic physiology of turkeys. Poultry Science. $1993 \mathrm{dec} ; 72$ (12): 2316-2327.

2. Moran Júnior ET. Digestion and absorption in fowl and events through prenatal development. Journal of Nutrition. 1985 may; 115(5): 665-674.

3. Tako E, Ferket PR, Uni Z. Effects of in ovo feeding of carbohydrates and $\beta$-hidroxy- $\beta$-methylbutyrate on the development of chicken intestine. Poultry Science. 2004 dec; 83(12): 2023-2028.

4. Uni Z, Ferket RP, inventors; North Carolina State University, Raleigh, NC; and Yissum Research Development Company of Hebrew University of Jerusalem, assignee. Enhancement of oviparous species by in ovo feeding. US Patent 6.592.878. 2003 Jul 15.

5. Foye OT, Uni Z, Ferket PR. Effect of in ovo feeding egg white protein, beta-hydroxy-beta-methylbutyrate, and carbohydrates on glycogen status and neonatal growth of turkeys. Poultry Science. 2006. jul 85 (7):1185-1192.

6. Tarachai P, Yamauchi K. Effects of luminal nutrient absorption, intraluminal physical stimulation, and intravenous parenteral alimentation on the recovery responses of duodenal villus morphology following feed withdrawal in chickens. Poultry Science.2000 nov;79(11): 1578-1585.

7. Foye OT, Ferket PR, Uni Z. The effects of in ovo feeding arginine, $\beta$-hydroxy- $\beta$-methyl-butyrate, and protein on jejunal digestive and absorptive activity in embryonic and neonatal turkey poults. Poultry Science. 2007 dec; 86 (12):2343-2349.

8. Ipek A, Sahan U, Yilmaz B. The effect of in ovo ascorbic acid and glucose injection in broiler breeder eggs on hatchability and chick weight. Archiv für Gerflügelkunde. 2004 mar; 68(3):132-135.

9. Uni Z, Ferket RP, Tako E, Kedar O. In ovo feeding improves energy status of late-term chicken embryos. Poultry Science. 2005 may; 84(5): 764-770.

10. Smirnov A, Tako E, Ferket PR, Uni Z. Mucin gene expression and mucin content in the chicken intestinal goblet cells are affected by in ovo feeding of carbohydrates. Poultry Science. 2006 apr; 85(4): 669-673.

11. Bruzual JJ, Peak SD, Brake J, Peebles ED. Effects of relative humidity during incubation on hatchability and body weight of broiler chicks from young breeder flocks. Poutry Science. 2000 jun;79 (6): 827-830

12. Noble RC, Lonsdale F, Conner K, Brown, D. Changes in lipid metabolism of the chick embryo with parent age. Poultry Science. 1986 mar; 65(3):409-416.

13. Shanawany MM. Inter-relationship between egg weight, parental age and embryonic development. British Poutry Science. 1984 mar; 25(3): 449-455.

14. Hearn, PJ. Making use of small hatching eggs in an integrated broiler company. British Poultry Science. 1986 mar; 27(3) 498-501.

15. Vieira SL, Moran Júnior ET. Eggs and chicks from broiler breeders of extremely different age. Journal of Applied Poultry Research. 1998 apr;7(4): 372-376.

16. Vieira SL, Moran Júnior ET. Effect of egg origin and chick post-hatch nutrition on broiler live performance and meat yields. World's Poultry Science Journal. 1999 may; 
55(2): 125-142.

17. Leitão RA, Leandro NSM, Stringhini JH, Café MB, Pedroso AA, Chaves LS. Inoculação de glicose em ovos embrionados de frango de corte: parâmetros de incubação e desempenho inicial. Ciência Animal Brasileira. 2008 dec; 9(4): 847-855.

18. Rostagno HS, Silva DS, Costa PMA, Fonseca JB, Soares PR, Pereira JAA, Silva MA. Tabelas brasileiras para aves e suínos: Composição de alimentos e exigências nutricionais. 2. ed. Viçosa: UFV, 2005. 141 p.

19. Uni Z, Ganot S, Skland D. Posthatch development of mucosal function in the broiler small intestine. Poultry Science. 1998 jan; 77(1):75-82.

20. STATISTICAL ANALYSES SYSTEM - SAS. User's Guide. Version 6.11. Cary: 1998. 634p.
21. Sampaio IBM. Estatística aplicada à experimentação animal. 2. ed. Belo Horizonte: FEPMVZ, 1998. 221 p.

22. Ohta Y, Kidd MP, Ishihashi T. Embryo growth and aminoacid concentration profiles of broiler breeder eggs, embryos and chicks after in ovo administration of amino acids. Poultry Science. 2001 oct; 80 (10):1430-1436.

23. Pedroso AA, Chaves LS, Lopes KLAM, Café MB, Leandro NSM, Stringhini JH. Inoculação de nutrientes em ovos de matrizes pesadas. Revista Brasileira de Zootecnia. 2006 oct; 35(5): 218-226.

24. Leitão RA, Leandro NSM, Stringhini JH, Café MB, Andrade MA. Inoculação de maltose, sacarose ou glicose em ovos embrionados de baixo peso. Acta Scientiarum. Animal Sciences. 2010 jan; 32(1): 93-100.

Protocolado em: 24 ago. 2008. Aceito em: 10 set. 2013. 